Available in the SSRN eLibrary: http://ssrn.com/link/2016-ENTRENOVA.html Innovation Research \& Policy Network (IRPN)

\title{
An Alternative to Online Travel Agencies for Retention of Hotel Customers
}

\author{
Riccardo Bonazzi \\ University of Applied Sciences Western Switzerland (HES-SO Valais/Wallis) \\ Roland Schegg \\ University of Applied Sciences Western Switzerland (HES-SO Valais/Wallis)
}

\section{Abstract}

This paper describes a service that allows hotels to reduce their dependency form online travel agencies, such as Booking.com or Expedia. Online travel agencies are extremely helpful to increase the number of new reservations of most hotels, but they seem to be less effective for niche hotels that seek for recurring customers. By following the guidelines for design research, we seek to develop a new online service, which combines existing solutions to (1) acquire new clients, (2) book a room on the website of the hotel and (3) retain the customer after service delivery. We illustrate a case study of a hotel, which has reduced the number of clients obtained via Booking.com by following our guidelines.

Keywords: online travel agency, hotel, business model innovation, tourism JEL classification: L8, Z3

Acknowledgments: The approach of this study is based on courses given by E. Fragnière, $\mathrm{K}$. Varini, N. Sarrasin, R. Schegg, and J.C. Loubier. The authors would like to thank Louizos and Lisa Papadopoulos for their support.

\section{Context Analysis}

Swiss Tourism is subject to significant challenges. In addition to the unfavourable economic climate, the Swiss hotel industry is facing new entrants among online travel agencies (e.g. AirBnB, HouseTrip, HomeAway), new alternative products and distribution networks, which are causing a strong rivalry between the accommodation sector companies (Scaglione and Schegg, 2015; Schegg et al., 2013).

Smaller destinations strive to be innovative by focusing on unique and local experience. This gave rise to charming products, called "boutique hotel", highlighting a style based on a unique concept and personality. This movement has led many consumers to abandon major destinations for areas offering the most authentic and surprising experiences (Ali, 2015). Now boutique hotels focus their attention on what they have to offer different and how they can make themselves known. They focus on finding intelligent and effective ways to market their concept, seeking to reach visitors outside the traditional channels and advertising.

According to a study performed by the Institute of Tourism of the HES-SO Valais/Wallis, one fourth of hotel reservations made in Switzerland in 2014 used an online booking platform (Larpin et al., 2015). Meanwhile, the online travel agencies (e.g. Booking.com, Expedia, TripAdvisor) continue their fast growth and they became indispensable partners for $75 \%$ of hotels. The influence of online travel agencies is mostly found on small independent hotels under 50 rooms. This market is dominated by the giant Booking.com counting almost $71 \%$ of online bookings by 
2014; the commission received by Booking.com represents an annual sum of 30,000 francs for an average hotel which is about 700 francs per room each year. Hotels try to get rid of this addiction by seeking alternative means. One way is to join low-cost online channels as Booking Valais. The peculiarity of it is that bookings are made without commission. With this tool, the Valais hotels could save about 680,000 francs and turnover has also more than doubled Booking Valais in 2014(Rhône FM, 2015). In this paper, we present the case of Maya Boutique Hotel in Nax, a luxury hotel next to Sion (more information on maya-boutique-hotel.ch). The Maya Boutique Hotel is currently redefining its strategy for acquiring new customers after having won the Best Innovation in Hotel Concept prize by the (Hospitality Awards, 2015) and the Sustainability prize by the (Boutique Hotel Awards, 2015). The next sections show how we used design thinking tools to find insights for new value propositions and new products to develop. We did so by formalizing the assumptions made about the hotel guests (section 2), by analyzing the spatial distribution of customers (section 3 ), by doing quantitative tests on client data and company data from the site (section 4) and by completing quantitative tests with qualitative interviews to understand more deeply a customer segment (section 5).

\section{Identification of customer segments}

Maya Boutique Hotel identifies two customer segments, which have been associated to two fictional characters, also known as persona: (a) François for French customers and (b) Delia for German-speaking clients.

Figure 1 shows that each person has been associated with a specific reservation process in order to adapt the multi-channel strategy to help them choose the hotel. The demographic characteristics of two fictional characters used to design two different marketing strategies to identify potential customers. The needs of each fictional character (pain/ gain) are used to adapt the message of our promotions to increase conversion rates. The following section shows the tests done to verify the assumptions made about the two fictional characters.

Figure 1

Persons for French and German speaking customers

\begin{tabular}{|c|c|}
\hline Francis, the stressed person & Delia, ecologist \\
\hline $\begin{array}{l}\text { "I am looking for a quiet place where I can } \\
\text { relax with my wife" }\end{array}$ & "I seek a place in contact with nature" \\
\hline o Age: 40 & o Age: 45 \\
\hline o City: Geneva & o City: Zurich \\
\hline o Language: French & o Language: \\
\hline o Duration of booking: 1 day & o Duration of booking: 2 days \\
\hline Booking process & Booking process \\
\hline 1. Plan ahead the weekend & 1. Plans vacation \\
\hline 2. Receive advice by a client & 2. Sees an article on a newspaper \\
\hline 3. Control on Booking.com & 3. Control on Booking.com \\
\hline 4. Made reservation & 4. Made reservation \\
\hline 5. Travel by Car Features & 5. Train Tour Features \\
\hline Pain & Pain \\
\hline o Weather & o Things to Do \\
\hline o Uncertainty & o Information available \\
\hline
\end{tabular}

Source: Authors 


\section{Spatial analysis of changing customer}

Spatial analysis of the evolution of customer uses the list of bookings made at Maya Boutique Hotel in the last three years. For each reservation, one can see on Google Maps customer address, changing the colour of the point by year (for 2013 light blue, dark blue and red for 2014 to 2015). Figure 2 shows how between 2013 and 2015, one can identify (a) a group of customers who live in Lake Geneva and can be associated with the fictional character Francois and (b) a group of clients who seems to inhabit prevalence around major German cities and one can associate with the fictional character Delia.

Figure 2

Evolution of customers in Switzerland between 2013 (top left), 2014 (Lower left) and 2015 (Bottom right)
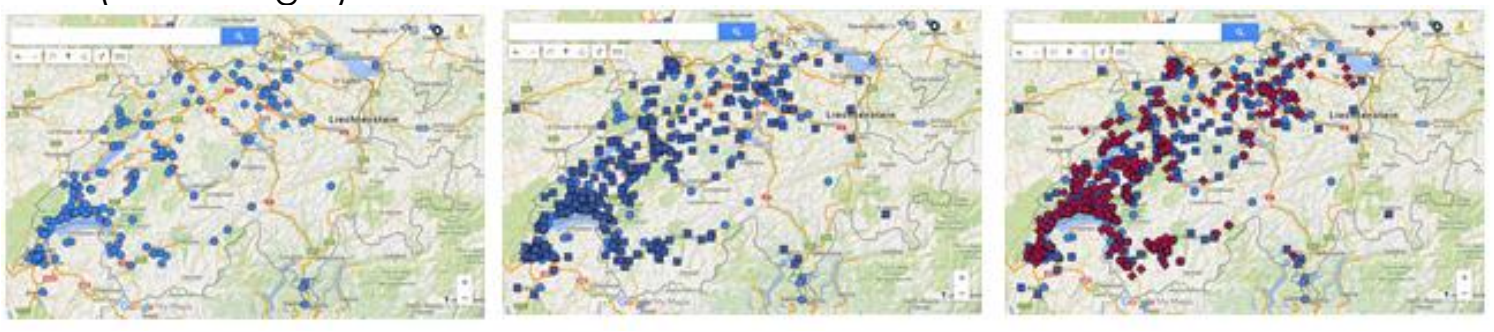

Source: Authors

This analysis allows us to identify two areas in Switzerland, which represent a great potential for improvement and that should be taken into account by the Maya Boutique Hotel. The German-speaking part of the region of Valais is not sufficiently represented among existing customers, and this can be explained by the presence of luxury hotels in Zermatt. Moreover, figure 3 shows that the Ticino is where people seek the word "boutique" with the highest frequency in Switzerland. However, there is almost no customer from Ticino and this is because there is not yet marketing strategy for the Italian-speaking customers.

Figure 3

The results Google Trends (2015) for "Boutique Hotel" in Switzerland demonstrate the potential of Ticino

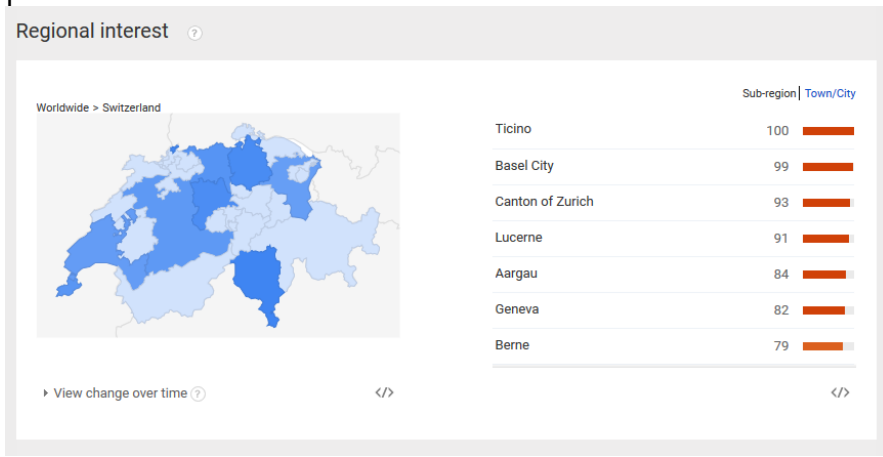

Source: Authors

\section{Quantitative analysis of customer segments}

Figure 4 shows statistical tests on the length of customer stays between 2013 and 2015. We can verify that French-speaking clients tend to stay less than the German- 
speaking clients. This might be due to (a) different types of stay (romantic Vs getaway in nature) and (b) a greater distance from German-speaking cities.

Figure 4

Distribution of length of stay for French customers (FR) and German (DE)

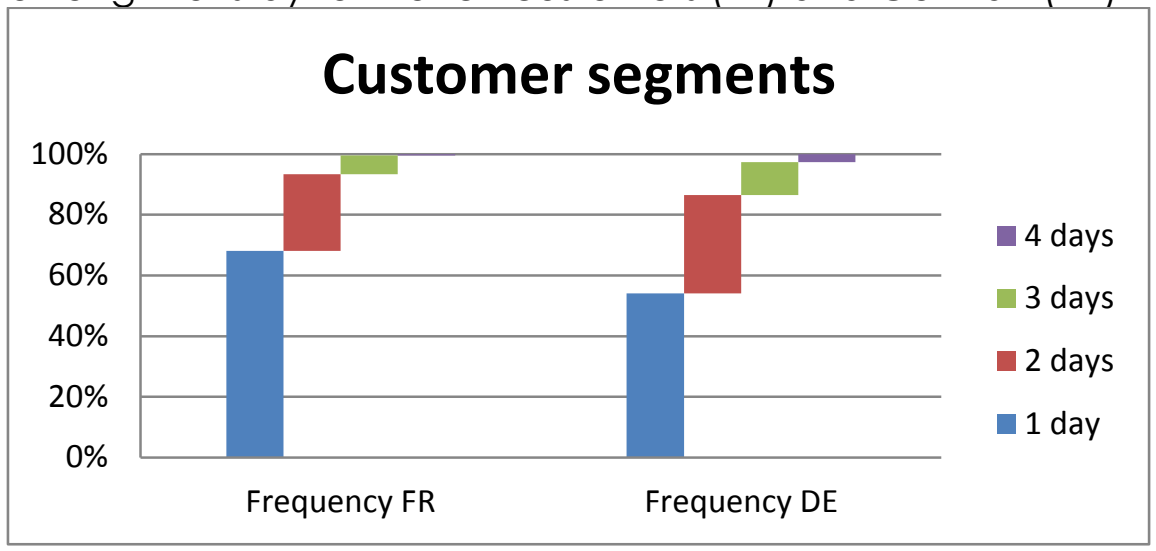

Source: Authors

By analyzing the data of the website and shown in figure 5 , we see that French speaking clients find the hotel by using the search engine Google (mostly by using the words "romantic weekend Suisse"). In comparison, the majority of German visitors arrived on the site through other websites, such ausflugsziele.ch and mont-nobletourisme.ch. Hence, the hotel should increase the budget for promotion campaigns in French through Google AdWords and it should renew the partnership with German tourist sites.

Figure 5

Comparison of sources of acquisition of web visitors in December 2014 (left) and December 2015 (right)

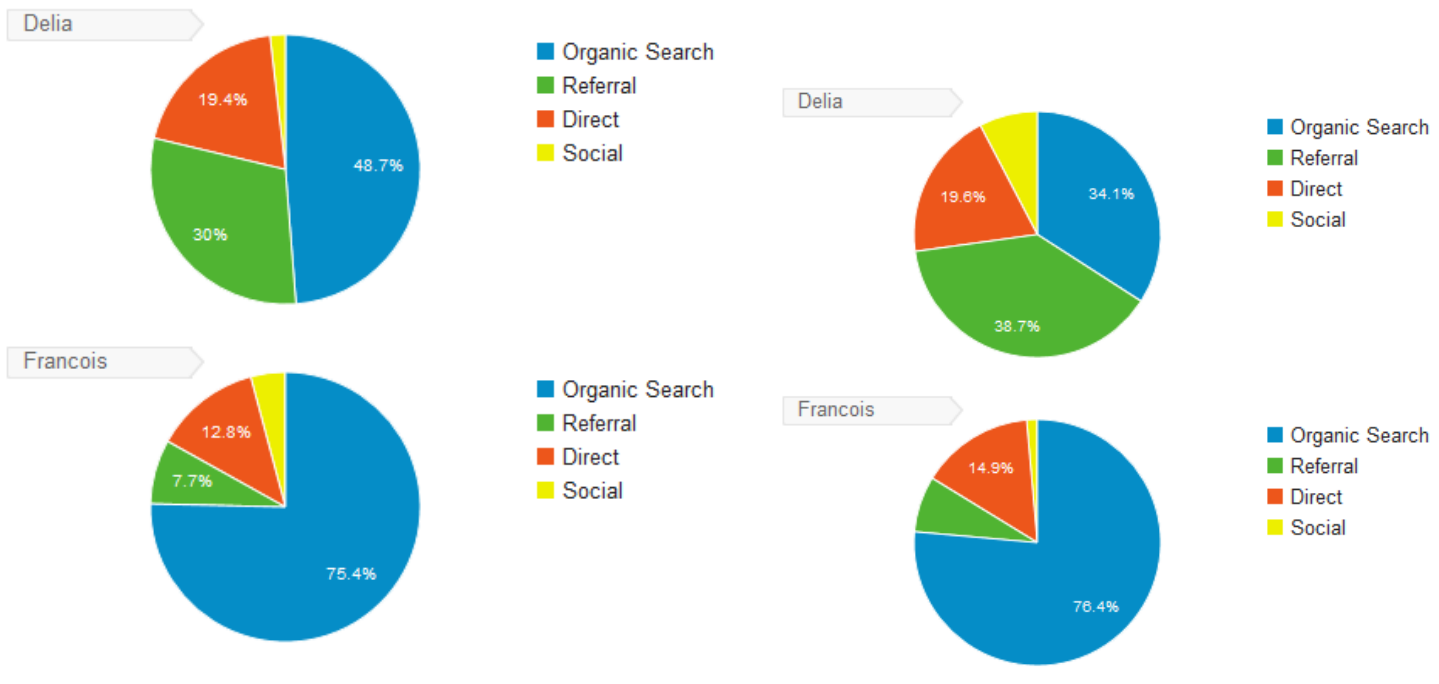

Source: Authors

\section{Qualitative analysis of customer needs for a romantic holiday}

The service design team of HES-SO conducted a dozen interviews with hotel guests and potential customers who reside around the Geneva Lake. Generally speaking 
respondents perform an extensive research on the internet before booking their room for a romantic holiday. The choice of hotel is defined primarily by the location and time and dates. Pictures, descriptions, rating and especially the comments of former clients become formidable tools in decision making. Results found on Booking.com, combined with analysis of information on TripAdvisor has become an absolute must in order to plan and choose the hotel offering the best services, benefits, price and experience. For a romantic stay, respondents look for a place with beautiful surroundings and breathtaking views. The hotel must have a particular style with spacious rooms with all amenities and services expected of an establishment of high-end. They prefer hotels with a Spa and Wellness. The food is also important: something in the discovery and surprising, out of the ordinary. Respondents already spent romantic weekends in hotels and, for the most part have had good experiences. But they feel that packages do not fully meet their needs, and that such bundled offers should be customized by the client. In this sense, a flexible or adaptable package would be more interesting. Respondents know that customer acquisition and retention are key priorities for the hotel and they gladly make recommendations if the experiment is successful. But they feel overwhelmed by the number of loyalty programs on the market. In an upscale hotel, respondents prefer a softer and less direct approach. To attract new customers to join the loyalty program it is sometimes better to offer something of value to them as a free service, a meal or a bottle of champagne, instead of a prize reduction.

\section{Discussions and conclusions}

At the end of our intervention, Maya Boutique Hotel limited the number of reservations obtained via booking.com and significantly improved the reservations done directly from their website.

Figure 6

Hotel Discovery Process, reservation and affiliate programs

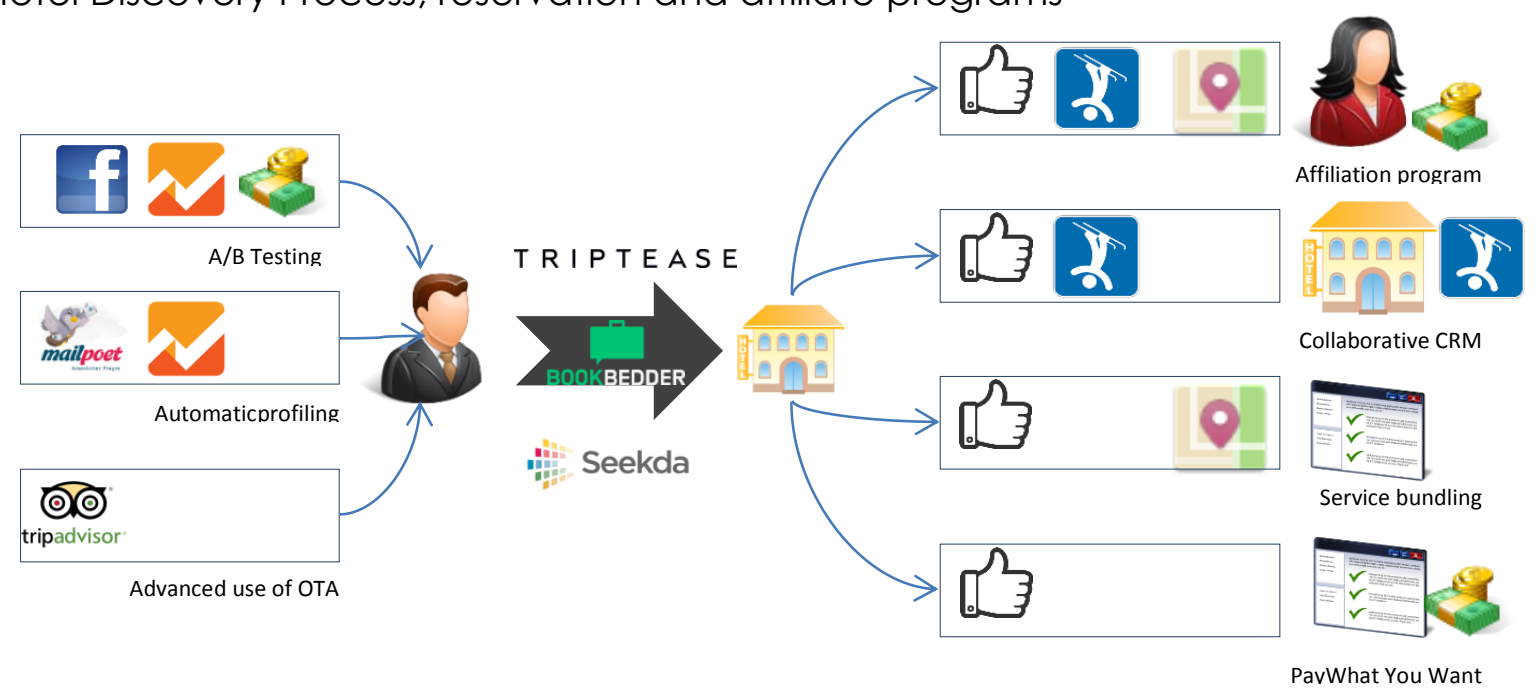

Source: Authors

Nonetheless, since we have performed only one case study, we cannot determine with precision how much of this result is due to our intervention and how much is due to external factors.

Future directions of investigations concern the design for a system, which should be used as a complement to OTA. Figure 6 illustrates a process that allows hotels to set 
up a strategy of acquisition and additional loyalty and partially freed from OTAs. By observing the online behaviour of its client, the hotel can improve its strategy for customer acquisition. Figure 6 shows different types of online tools that complement Booking.com. The hotelier will be able to use different alternatives to online booking as Triptease, Seedka or the new service Bookbedder.com. Then, if the client has enjoyed the hotel, the facilities and location, the hotel owner should include him in a loyalty program. If the customer has enjoyed only the hotel and activities, it is preferable to use a collaborative CRM to propose another location corresponding to expectations of the customer. If the customer has enjoyed the hotel but looks for different activities, the hotelier can choose a tool to dynamically bundle activities into a set of modular offers.

\section{References}

1. Ali, R. (2015), "Top Travel Trends for 2015: New Skift Magazine", Skift, 13 January, available at: http://skift.com/2015/01/13/new-skift-magazine-megatrends-definingtravel-in-2015/ (24/1/2016)

2. Boutique Hotel Awards (2015), "Sustainability - Boutique Hotel Awards", available at: http://www.boutiquehotelawards.com/hotel-experiences/sustainability-2015/ $(1 / 3 / 2016)$

3. Hospitality Awards (2015), "Best innovation in hotel concept", available at: http://hospitalityawards.com/en/the-categories/hospitality-awards/2015/bestinnovation-in-hotel-concept/ (1/3/2016)

4. Larpin, B., Délétroz, N., Schegg, R. (2015), "Hébergement touristique: rénover, mais pour qui ? Analyse stratégique, attentes des hôtes et conséquences pour le secteur HES SO Valais publications - Aigaion 2.0", Salon de l'Habitat et de La Rénovation, available at: http://publications.hevs.ch/index.php/publications/show/1940 $(25 / 6 / 2016)$

5. Rhône FM (2015), "Rhône FM - Chiffre d'affaire plus que doublé pour Booking-Valais en 2014", available at: http://www.rhonefm.ch/fr/news/chiffre-d-affaire-plus-quedouble-pour-booking-valais-en-2014-282757 (25/6/2016)

6. Scaglione, M., Schegg, R. (2015), "The Impact of Attribute Preferences on Adoption Timing of Hotel Distribution Channels: Are OTAs Winning the Customer Race?", Information and Communication Technologies in Tourism 2015, Springer, pp. 681-693.

7. Schegg, R., Stangl, B., Fux, M., Inversini, A. (2013), "Distribution channels and management in the Swiss hotel sector", Information and Communication Technologies in Tourism 2013, Springer Berlin Heidelberg, pp. 554-565.

\section{About the authors}

Riccardo Bonazzi is a professor at the institute of entrepreneurship and management at HES-SO Valais. His main interests are business model design and he has conducted research on governance, risk and compliance management. The author can be contacted at riccardo.bonazzi@hevs.ch.

Roland Schegg is a professor at the institute of tourism at the HES-SO Valais. He can be contacted at roland.schegg@hevs.ch. 